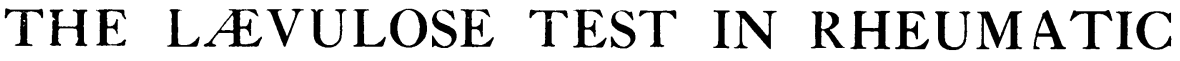 AND CHOREIC CHILDREN.*
}

\author{
BY
}

\author{
MIRIEL, J. BROWN, M.D., ID.P.H.
}

(From the Dept. of Paediatrics. (xlasgow University. and the Biochemical Laboratory, Royal Hospital for Sick Children, (Alasgow.)

In a paper recently published in The Archives of Disease in Childhood Taylor Chadwick' gave the results of an investigation of the behaviour of the lævulose test in the rheumatic child. From the results he concluded that in certain stages of the rheumatic infection the efficiency of the liver is impaired, and he expressed the opinion that this might be due to the result of toxic absorption from some rheumatic focus. In children completely recovered from rheumatism. and in those suffering from uncomplicated chorea, he found that the ingestion of lævulose gave a blood-sugar curve not differing from that obtained in the normal individual. In children presenting active rheumatism, with or without heart affection. and in the examples of chorea with evidence of carditis there was, on the other hand, an appreciable intolerance to lævulose as indicated by a rise in the blood sugar. This rise in the blood sugar varied between 18 per cent. and 113 per cent., with an average increase of 49 per cent.

A survey of the details in (hadwick's paper raises a suspicion that the diminished hepatic efficiency as indicated by the lævulose test is dependent on passive congestion of the liver secondary to cardiac involvement rather than on some toxic action. Of the number of cases in which there was cardiac involvement 54 per cent. reacted abnormally to lævulose. If, however, there be excluded the five cases (Nos. 12, 16, 30,31 and 34), in which the cardiac involvement was admittedly transient, then the percentage of abnormal findings in Chadwick's cardiac cases rises to 73. On the other hand, of the four rheumatic cases without apparent heart disease, only one (No. 11) gave an abnormal curve. In the text of his paper Chadwick drew attention to the cases with and withont heart disease, and while he remarked that the abnormal blood-sugar curve following lævulose bears no relationship to the valvular lesion, he admitted that it did bear a certain relationship to the state of tone of the cardiac muscle. It is, therefore, difficult to appreciate on what grounds he bases his ultimate conclusion that active rheumatism, with or without heart disease, is accompanied by an abnormal blood-sugar curve after the ingestion of lævulose.

In a previous communication², also published in this Journal, I recorded the results of a study of the value of the lavvulose test as an index of efficiency of the liver. I concluded that a rise of 30 per cent: in the blood-sugar content after the administration of lærulose should be considered as evidence of hepatic

* The work was carried ont under a grant from the Medical Research Council 
disease, but that wide variations below that figure occur in the normal child. Three of my control cases employed were children who had recently passed through an attack of rheumatic fever, but who had escaped any apparent cardiac involvement. In none of these cases was there any evidence of hepatic inefficiency. In one case of rheumatism with severe valvular disease of the heart and enlargement of the liver, there was found evidence of hepatic inefficiency; the increase in the blood sugar after the ingestion of lævulose amounted on two occasions to 42 per cent. and 43 per cent. respectively, which is well above the upper limit ( 30 per cent.) of the normal.

\section{Present Investigations.}

The following work was undertaken to investigate further the results of the lævulose test in a series of rheumatic and choreic children. As far as can be ascertained from a review of the case histories the type of patient investigated was the same as in Chadwick's series.

Maclean's method for estimating the blood-sugar content was employed throughout ; 20 to $30 \mathrm{grm}$. of Merck's pure lævulose, dissolved in $150 \mathrm{c.cm}$. of water, were administered per os, the amount depending on the age of the child. The blood-sugar estimations were made at half-hourly intervals after the ingestion of the lævulose until the blood sugar had returned to the normal fasting level. The importance of using the purest lævulose was noted in $\mathrm{my}$ previous paper.

In the grouping of the cases the same classification as was adopted by Taylor Chadwick was employed, but for better evaluation of the various phases of the rheumatic infection in producing the intolerance to lævulose, some of the groups have been further sub-divided.

\section{Group I.-Rheumatic arthritis without cardiac involvement. (Table I).}

Unfortunately I was only able to obtain one case which could be placed in this group. Thirteen days before the test was first performed this child had taken ill with fever, rapid pulse and pains in the hips, knees and wrists which persisted for nine days. For six days before the test the child had been on sodium salicylate, and for four days there had been no pain in any of the joints, and the temperature and pulse had remained normal. At this time there was a rise in the blood sugar of 32 per cent., which is slightly above the highest normal figure. The temperature and pulse remained within normal limits and there was no further complaint of any joint pains ; and three weeks still later, when the test was repeated, no rise in the blood sugar was obtained. The interesting point in this case is that a higher rise was obtained when the infection was more active than during convalescence.

Group II.-Convalescent rheumatic arthritis with cardiac involvement.

This group, the details of which are given in Tables II, III, and IV, has been subdivided into $(a)$ cases where the cardiac murmur was transient: (b) cases where there was definite cardiac disease but no signs of incompetency : and $(c)$ cases of severe cardiac disease with incompetence. 
(a) In considering the cases where the cardiac murmur was transient and there was no evidence of active rheumatic arthritis, one (No. 2) gave a definite rise in the blood sugar of 43 per cent., while the other (No. 3), gave only a rise of 7 per cent. Unfortunately a repeat test was not possible in Case 2, as the child vomited after the second dose of lævulose. (Table JI).

(b) Of the twelve examples of convalescent rheumatism with cardiac disease, none showed any abnormality in the behaviour of the blood sugar after the ingestion of lævulose. (Table III).

(c) There were five cases with severe cardiac disease and some degree of incompetenre, and two (Nos. 18 and 20) showed a definite rise in the blood sugar of 92 per cent. and 37 per cent. respectively. No. 18 also showed a delay in the return to the normal fasting level. This was a very severe case of cardiac failure with œdema of the feet and enlargement of the liver, in which an abnormal lævulose reaction was not unexpected. In another case (No. 20) the child appeared on clinical examination to be in the same state at the time of both tests, yet at the first examination a rise of 37 per cent. was obtained, while six days later the blood sugar remained practically level for two hours after the ingestion of the lævulose. (Table IV).

Group III.-Active chorea without cardiac involvement. (Table V).

In the five cases of this group in which the chorea was still active but in which there was no evidence of any involvement of the heart, two (Nos. 22 and 23), as seen in Table V, responded with a definite rise in the blood sugar of 40 per cent. and 45 per cent. respectively. In the other three cases the bloodsugar curve was normal. A repeat test was performed in one of them (No. 23) one month later when the chorea was less marked, but the rise obtained in the blood sugar was well within the limits of experimental error.

Group IV.-Active chorea with cardiac involvement. (Table VI).

This group consisted of twelve cases of active chorea with definite evidence of cardiac involvement, although in none was the cardiac disease very severe. Only two of these cases (Nos. 27 and 36) gave a definite rise in the blood sugar, an increase of 54 per cent. and 45 per cent. respectively being obtained. Repeat tests were performed in each, but no rise in the blood sugar was obtained in either on the subsequent occasions. In Case 36 there was definite improvement clinically at the time of the second examination, all the chorea having disappeared although the heart condition remained the same. Case 27, on clinical examination, appeared to be in the same condition on all three occasions.

Group V.-Convalescent chorea without cardiac involvement. (Table VII).

Three children (Nos. 38, 39 and 40) were examined a short time after all choreic movements had disappeared, and as is seen in Table VII, in none was there any definite increase in the blood sugar after the ingestion of the lævulose.

Group VI.-Convalescent chorea with definite cardiac disease. (Table VIII).

There are three cases (Nos. 41, 42 and 36, the last at the time of the second examination) which may be considered under this heading. Although the 
children had a definite heart lesion all the choreic movements had disappeared, and as in the case of convalescent chorea without any heart involvement, there was no evidence of any hepatic inefficiency as shown hy the lævulose test.

\section{Discession.}

From a general survey of the results (Table IX) in these various groups of rheumatic cases, it is impossible to appreciate any consistent behaviour towards lævulose during any one phase of the disease unless it be that convalescent chorea invariably reacts as in health, a normal curve always being obtained. The number in this group is, however, small, namely, six, and one does not therefore wish to draw far-reaching conclusions.

Contrary to expectations, cardiac disease, at least valvular disease, is not the determining factor, since of the total cases with heart involvement 12 per cent. reacted abnormally, whereas of those without heart disease 33 per cent. reacted abnormally. In this latter group again, however, the number is small, namely, nine.

It is, of course. the condition of the myocardium which is of moment in this connection, and it is just this factor which is most difficult to estimate. Cardiac disease was diagnosed in the above cases on the pres?nce of a murmur which, as is well known, may be a prominent sign even though the myocardium is quite efficient.

With the idea that the pulse rate would be a better gauge of the efficiency of the myocardium an attempt was made to correlate this with the lavulose test but without success. Of 26 cases with a pulse rate ranging from 70 to 90 per minute, 5 (20 per cent.), reacted pathologically : of 9 cases in which the pulse ranged between 90 and 100, only 1 ( 10 per cent.), reacted abnormally, and of 15 cases in which the pulse varied between 100 and 120 per minute, only 2 (12 per cent.), gave a rise in the blood sugar after lavulose of more than 30 per cent.

The group which gave the largest proportion of pathological results was that of active chorea, and again the larger proportion of abnormal results was obtained when no cardiac disease was apparent. It is just possible that in chorea there may result overstimulation of the sympathetic nerrous system with a consequent disturbance of carbohydrate metabolism.

These findings, it is seen, are very different from those obtained by Taylor Chadwick in his series of cases, and it is difficult to account for such discrepancies. It may be that the efficiency of the liver varies from time to time even in the normal individual, and that two small groups of cases, as undoubtedly both Chadwick's and mine are, will contain in very varying proportions these varying degrees of efficiency.

It is interesting that only one case in my series revealed, in addition to an abnormal rise in the level of the blood sugar, a delayed fall to the fasting level. In this case there was both clinical and pathological evidence of liver derangement (enlargement and passive congestion), and thus in gauging hepatic efficiency it might be advisable to consider not only the percentage rise, but the time taken for the normal level to be regained. In my previous communication 
on the lævulose test 76 per cent. of the 25 cases with definite hepatic disease showed an abnormal rise of the blood sugar, and of these 25, 60 per cent. presented a delayed fall. In 11 cases of probable hepatic disease an abnormal rise was obtained in 54 per cent., but in only 18 per cent. of these was there a delayed fall. while in 9 cases of problematical liver disease only 1 case showed an abnormal rise with also a delayed fall, and in 20 normal children none presented a rise of more than 30 per cent., and in no instance a delayed fall.

\section{Conclesions.}

1. The lævulose test was performed in 19 children who were suffering from convalescent rheumatic fever with definite cardiac involvement, and of these only 3 gave a rise in the blood sugar of more than 30 per cent. after the ingestion of lævulose.

2. One case of severe cardiac disease with definite clinical and pathological evidence of liver derangement, showed in addition to an abnormal rise in the blood sugar a delay in return to the fasting level.

3. Of 5 cases of active chorea in which there was no evidence of cardiac involvement, two gave a rise in the blood-sugar content of more than 30 per cent. after the ingestion of lævulose ; and of 12 cases of active chorea with definite cardiac disease, 2 gave an abnormal rise of blood sugar after the ingestion of lævulose.

4. In 6 cases of convalescent chorea, 3 of which showed evidence of cardiac disease, a normal blood-sugar curve was obtained.

5. Of 32 cases of rheumatic cardiac disease only 4 (12 per cent.) showed an abnormal rise after the ingestion of lævulose; whereas of 9 cases of the rheumatic infection without heart disease, 3 (33 per cent.) showed an increase in the blood sugar of more than 30 per cent.

6. The lævulose test gives no consistent evidence of liver derangement in the rheumatic infection.

\section{(For Tables see pages 81 and 82.)}

\section{REFERENCES'}

1. Chadwick, R. T., Arch. Dis. (Kild., Lond., 192๙, III, 179.

2. Brown, M. J., Ibid., 192๙, III, 81 . 
TABLES I-VI.

The Levulose Test in Rheunatic and Choreic ('hildrex.

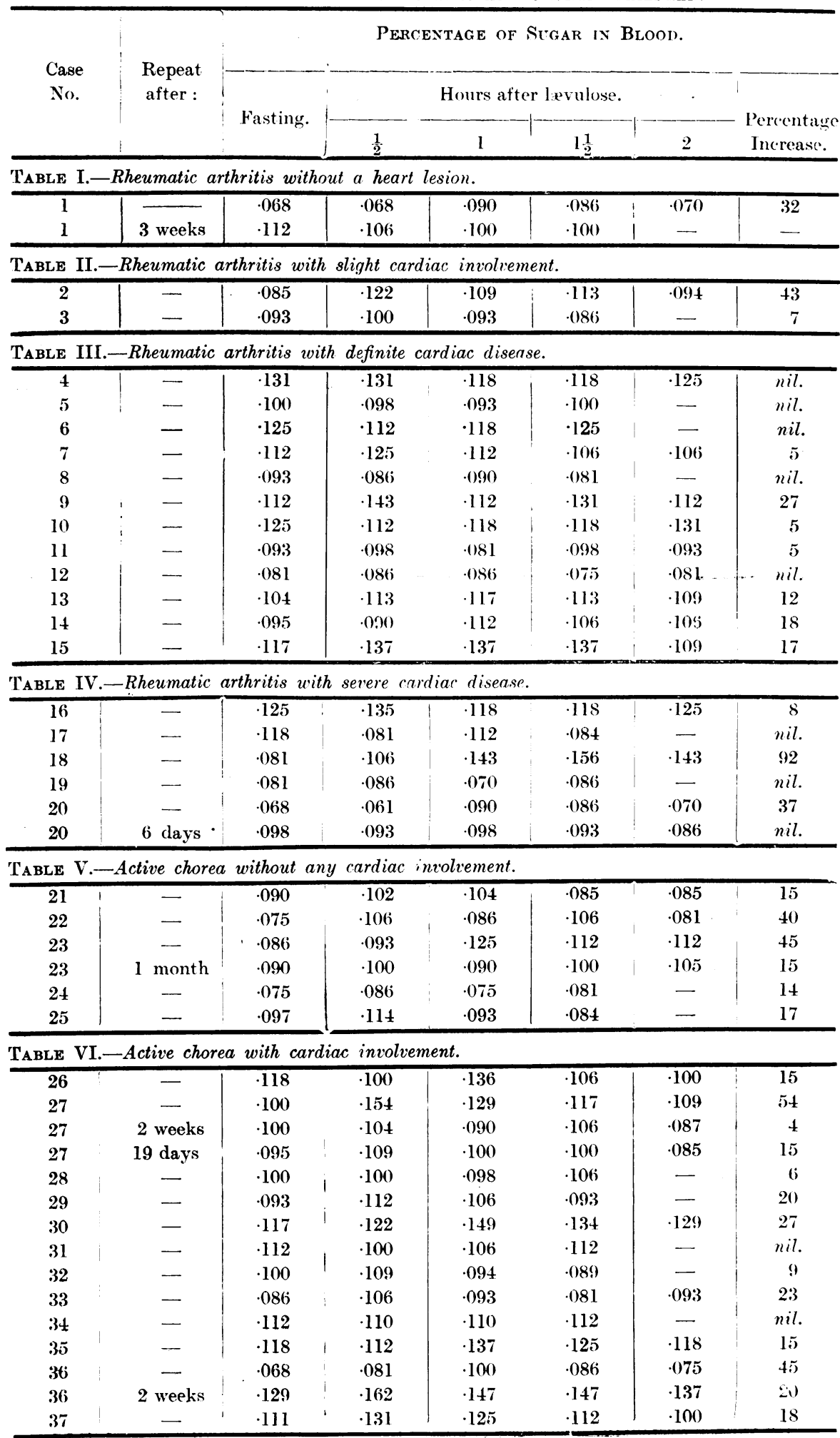


TABLES VII. AND VIII.

The Lavolose I'est in Rhematic and Choreic Children.

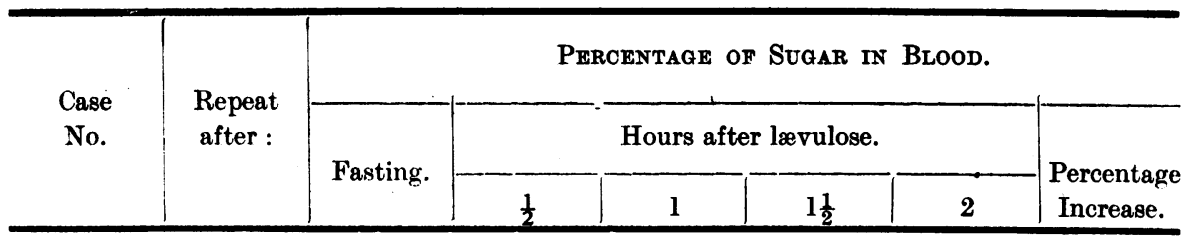

TABLE VII.-Convalescent chorea without cardiac involvement.

\begin{tabular}{r|r|c|c|c|c|c|c|c|}
\hline 38 & - & - & .094 & .094 & .109 & .097 & .094 & 15 \\
39 & - & .081 & .100 & .089 & .072 & - & 20 \\
40 & - & .086 & .086 & .081 & .090 & - & nil. \\
\hline
\end{tabular}

TABLE VIII.-Convalescent chorea with cardiac disease.

\begin{tabular}{|c|c|c|c|c|c|c|c|}
\hline 41 & - & .093 & .085 & .085 & .085 & - & nil. \\
\hline 42 & - & .082 & .082 & .077 & .082 & .077 & 5 \\
\hline 42 & 5 weeks & .088 & .094 & .094 & .088 & - & 7 \\
\hline $\begin{array}{c}36 \\
(\text { 2nd test })\end{array}$ & & .129 & $\cdot 162$ & $\cdot 147$ & $\cdot 147$ & $\cdot 137$ & 20 \\
\hline
\end{tabular}

TABLE IX.

Summary of Results.

\begin{tabular}{|c|c|c|c|c|c|c|c|}
\hline \multicolumn{5}{|l|}{. } & $\begin{array}{l}\text { Total } \\
\text { No. }\end{array}$ & $\begin{array}{c}\text { No. of } \\
\text { positive } \\
\text { lævulose } \\
\text { tests. }\end{array}$ & $\begin{array}{c}\text { Percentage } \\
\text { of positive } \\
\text { lævulose } \\
\text { tests. }\end{array}$ \\
\hline \multirow{2}{*}{$\begin{array}{l}\text { Cases with heart involvement } \\
\text { Cases without heart involvement }\end{array}$} & ... & ... & ... & ... & 32 & 4 & 12 \\
\hline & ... & $\cdots$ & ... & ... & 9 & 3 & 33 \\
\hline $\begin{array}{l}\text { Cases without heart involvement } \\
\text { Cases of convalescent arthritis }\end{array}$ & $\ldots$ & $\ldots$ & $\ldots$ & $\ldots$ & 20 & 4 & 20 \\
\hline \multicolumn{5}{|c|}{ Cases of convalescent arthritis with heart involvement $\ldots$} & 19 & 3 & 16 \\
\hline \multicolumn{5}{|c|}{ Cases of convalescent arthritis without heart involvement } & 1 & 1 & 100 \\
\hline Cases of active chorea $\quad \ldots$ & $\ldots$ & ... & $\ldots$ & $\cdots$ & 17 & 4 & 25 \\
\hline \multicolumn{5}{|c|}{ Cases of active chorea with heart involvement } & 12 & 2 & 16 \\
\hline \multicolumn{5}{|c|}{ Cases of active chorea without heart involvement } & $\mathbf{5}$ & 2 & 40 \\
\hline Cases of convalescent chorea & $\ldots$ & & & $\ldots$ & 6 & $\mathbf{0}$ & $\mathbf{0}$ \\
\hline \multirow{2}{*}{\multicolumn{5}{|c|}{$\begin{array}{l}\text { Cases of convalescent chorea with heart involvement } \\
\text { Cases of convalescent chorea without heart involvement }\end{array}$}} & 3 & $\mathbf{0}$ & 0 \\
\hline & & & & & $\mathbf{3}$ & $\mathbf{0}$ & $\mathbf{0}$ \\
\hline \multirow{2}{*}{\multicolumn{3}{|c|}{$\begin{array}{l}\text { Cases of chorea with heart involvement } \ldots \\
\text { Cases of chorea without heart involvement }\end{array}$}} & $\ldots$ & $\ldots$ & 15 & 2 & 13 \\
\hline & & & $\ldots$ & $\ldots$ & 8 & 2 & 25 \\
\hline
\end{tabular}

